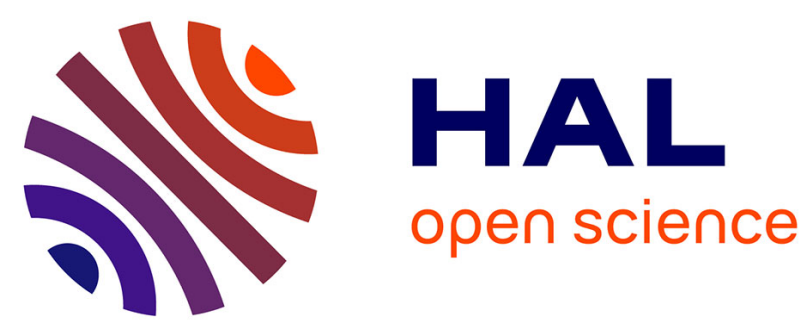

\title{
Definition Management Zones of Drip Irrigation Cotton Field Based on the GIS and RS
}

\author{
Ze Zhang, Zhouyang Li, Lulu Ma, Xin Lv, Lifu Zhang
}

\section{To cite this version:}

Ze Zhang, Zhouyang Li, Lulu Ma, Xin Lv, Lifu Zhang. Definition Management Zones of Drip Irrigation Cotton Field Based on the GIS and RS. 10th International Conference on Computer and Computing Technologies in Agriculture (CCTA), Oct 2016, Dongying, China. pp.508-517, 10.1007/978-3-03006155-5_52. hal-02179995

\section{HAL Id: hal-02179995 \\ https://inria.hal.science/hal-02179995}

Submitted on 12 Jul 2019

HAL is a multi-disciplinary open access archive for the deposit and dissemination of scientific research documents, whether they are published or not. The documents may come from teaching and research institutions in France or abroad, or from public or private research centers.
L'archive ouverte pluridisciplinaire HAL, est destinée au dépôt et à la diffusion de documents scientifiques de niveau recherche, publiés ou non, émanant des établissements d'enseignement et de recherche français ou étrangers, des laboratoires publics ou privés. 


\title{
Definition management zones of drip irrigation cotton field based on the GIS and RS
}

\author{
Ze Zhang ${ }^{1}$, Zhouyang $\mathrm{Li}^{2}$,Lulu $\mathrm{Ma}^{1}{ }^{1}$ Xin $\mathrm{Lv}^{1(\varpi)}$ and Lifu Zhang ${ }^{1,3(\varpi)}$ \\ 1. Shihezi university agronomy, Xinjiang Shihezi City, 832003, China \\ lxshz@126.com; zhanglf@radi.ac.cn \\ 2. Corps reconnaissance design institute of surveying and mapping branch of geographic information \\ ter ,Xinjiang Urumqi,830000,China \\ 3. Institute of Remote Sensing and Digital Earth, Chinese Academy of Sciences, Beijing, 100101, China \\ zhanglf@radi.ac.cn
}

\begin{abstract}
A fuzzy c-means clustering algorithm was used to assign soil nutrient to management zones which was based on remote sensing as data source in Nongwushi 81 Tuan Xin Jiang drip irrigation in cotton based on GIS and RS. The results showed that the variation coefficient of nutrient index was decreased in management zones based on remote sensing data source, space distribution were all the same direction. There were no significant differences among the three management zones. The space variation of soil nutrient content was different lowest in the same management zone. The conformity degree of the integration of management zones based on remote sensing NDVI as data was reached75.47\%.A fuzzy c-means clustering algorithm which was based on remote sensing as data source can achieve good management zones results, which could be used to help guide the rate of variable inputs and precise fertilizer application and provide the theory basis of soil nutrient management in cotton.
\end{abstract}

Keywords: GIS · RS · management zones · fuzzy clustering

\section{Introduction}

Precision agriculture, with over ten years of development, has become mature in term of many technologies, however, the effects on improve the environment and economic returns always haven't confirmed, so the management zone technology provide a effective means for this problem[1-2]. In recently years, it is a study focus for precision agriculture in international that through soil, crop variability on space-time, then research and study accurate management zone and make variable rate fertilization. This technology can significantly improve soil nutrient utilization efficiency so that get the purpose of protect agriculture resources and environmental quality.

Xinjiang Production and Construction corps is the very important production base for cotton planting, and agriculture industry has some specialties, such as large farmland size, high level of mechanization, centralized management, the conditions of natural climatic are same in all countries, great scale for drip irrigation under plastic film etc. [3]. However, some blind investments are founded and it continue to increase for inputting agricultural means of production such as chemical fertilizer etc. in part of cotton high yield regions, thus cause to agricultural resources use ratio is low, but it is hard to achieve that variable rate fertilization technology in large farmland, which take small scale regular net as working unit. Study spatial variation law of farmland soil nutrient characteristics and unify working unit of divide various nutrients for variable rate fertilization management, which has important theoretical significance and practical value [4]. It is necessary to further research and explores its feasibility and precision by remote sensing data for making management zone because the management zone study which based on remote sensing information is not completely.

*Address correspondence to these authors at Shihezi university agronomy,Shihezi 832003,Xinjiang; Tel: +8613909931721; E-mail: lxshz@126.com;

And Institute of Remote Sensing and Digital Earth,Chinese Academy of Sciences, Beijing, 100000, China;

Tel: +8613716974736; E-mail: zhanglf@radi.ac.cn 
This study regards drip irrigation cotton in crop 81,5th agriculture partition, Xinjiang production and construction corps as target objects, under the basis of previous study, research and explore feasibility and precision by remote sensing data for making management zone in order to provide reference for crop zone differentiated management and accurate and reasonable variable rate fertilization in larger regional unity working unit which divide variable rate fertilization by remote sensing information.

\section{Materials and methods}

\subsection{Obtain remote sensing data}

The study area as per cotton growing phonological phase, adopt Landsat-5 TM image (provided by Yaoxing tiandi information technology Beijing co,;ltd) and received date is on 13th Sep, 2011, total image size is half image (one image equal to $360 \mathrm{~km} * 360 \mathrm{~km}$ ), spatial resolution is $30 \mathrm{~m} * 30 \mathrm{~m}$, track No 146/29, including 7 wave band and vegetation information were displayed very well. The TM remote sensing image is being processed and analyzed by use ENI4.3 software. Two kinds vegetation index related crop growth NDVI and RVI were obtained (as following table 1) and combine with ground checking data so that establish remote sensing model of crop estimate. In accordance with precision inspect, the model is regression model for NDVI and cotton yield, index functional equation $y=1300.7 \mathrm{e} 2.423 x$, the maximum value of related coefficient $R^{2}$ is 0.8469 , and its crop estimate precision reach to $83.68 \%$. The cotton yields in bar-type farmland land that can't be tested were estimated by use this model.

Table 1. The type of vegetation index.

\begin{tabular}{ccc}
\hline Spectrum parameter vegetation & Algorithms & References \\
index & NDVI=TM4-TM3/TM4+TM3 & Rouse, et al. (1974) \\
NDVI & RVI= TM4/ TM3 & Pearson \& Miller (1974) \\
RVI & . & \\
\hline
\end{tabular}

\subsection{Zone partition method and confirm of suitable zone number}

Fuzzy-c mean value clustering is a usual unsupervised clustering method, which has been large used to classify for soil, landform data, output data and remote sensing data etc and also can resolve natural phenomena with continuity variation. The study applies the method of fuzzy-c mean value clustering algorithm for dividing zone, and apply optimal value after repeated combination which proposed by McBratney and Moore so that confirm proper zone number, i.e. derivation function related to $\varphi$ -

$[(\delta \mathrm{J} / \delta \varphi) \mathrm{c} 0.5]$, make the minimum c value of peak value is optimal choice, the location which peak is maximum is optimal choice [5-8] after the c value had been selected.

\subsection{Data processing and analysis}

The fuzzy-c mean value clustering is being realized by Matlab7.0 programming. And Spss17.0, GS+7.0 and ArcGIS9.3 are all used to realize data foundation statistics and analysis, special variability characteristics analysis of fuzzy membership, semi-variogram calculation, matching for theoretical model and graphic plotting of Krig-ing interpolation.

\section{Results and analysis}

\subsection{Soil property and vegetation index descriptive statistics}

Table 2 is soil nutrients index obtained from soil test and vegetation index selected from remote sensing image in study area, then we can obtain statistics characteristic value by making traditional analysis to vegetation index.

Table 2. Soil fertility and vegetation index of descriptive statistics 


\begin{tabular}{cccccc}
\hline Name & Minimum & Maximum & Mean & S.D & C.V \\
OM & 2.00 & 48.02 & 13.7982 & 5.21019 & $37.76 \%$ \\
AN & 11.00 & 167.38 & 72.1121 & 30.27736 & $41.99 \%$ \\
AP & 1.68 & 30.56 & 11.3934 & 5.48272 & $48.12 \%$ \\
AK & 94.69 & 713.00 & 246.0395 & 105.58577 & $42.91 \%$ \\
ACu & 0.19 & 2.45 & 1.1297 & 0.38608 & $34.17 \%$ \\
AFe & 0.79 & 8.50 & 3.9725 & 1.48951 & $37.50 \%$ \\
AZn & 0.08 & 4.57 & 0.7155 & 0.60326 & $84.31 \%$ \\
AB & 0.08 & 4.57 & 1.1343 & 1.03690 & $91.41 \%$ \\
AMn & 1.35 & 20.94 & 7.6769 & 3.40569 & $44.36 \%$ \\
Total salt & 0.13 & 0.81 & 0.39 & 0.14 & $35.42 \%$ \\
NDVI & 0.06 & 0.75 & 0.5154 & 0.18597 & $36.08 \%$ \\
RVI & 0.21 & 6.92 & 3.6637 & 1.47626 & $40.29 \%$ \\
Yield & 1507.29 & 8009.24 & 4973.8984 & 1806.22872 & $36.31 \%$ \\
\hline
\end{tabular}

From table 2 we can know that according to grading standard which is the second general survey in nationwide, organic matter, alkali-hydrolyzale nitrogen in study area are be in level of lower, rapid available phosphorus, available $\mathrm{Zn}$ and manganese are be in moderate level, rapidly available potassium and available $\mathrm{Cu}$ are be in very high level, available Fe are deficiency. Soil nutrients index variation coefficient is between $34.17 \%$ and $91.41 \%$, the vegetation index var iation coefficient that obtained from remote sensing image in study area is between $36.08 \%$ and $40.29 \%$. So it complies with management zone and implements variable rate fertilization because each index is displaying medium spatial

variation.

\subsection{Obtain management zone index and zone method}

We can get related matrix by cotton yield data obtained from remote sensing estimate, soil property, remote sensing index and making related analysis (see table 3)

Table 3. Study area of soil properties and crop yield, vegetation index correlation coefficient matrix

\begin{tabular}{|c|c|c|c|c|c|c|c|c|c|c|c|c|c|}
\hline & $\mathrm{OM}$ & AN & $\mathrm{AP}$ & AK & $\mathrm{ACu}$ & $\mathrm{AFe}$ & AZn & $\mathrm{AB}$ & AMn & T-salt & NDVI & RVI & Yield \\
\hline $\mathrm{OM}$ & 1 & $0.434^{* *}$ & $0.378^{* *}$ & $0.393 *$ & $0.402^{* *}$ & $0.338 * *$ & $0.277 * *$ & $0.117^{* *}$ & $0.421^{* *}$ & $-0.182 * *$ & $0.318^{* *}$ & $0.300 * *$ & $0.540^{* *}$ \\
\hline AN & $0.434^{* *}$ & 1 & $0.397^{* *}$ & $0.359 * *$ & $0.571^{* *}$ & $0.691^{* *}$ & $0.107^{* *}$ & -0.002 & $0.811 * *$ & $-0.107 * *$ & $0.284 * *$ & $0.245 * *$ & $0.441 * *$ \\
\hline AP & $0.378^{* *}$ & $0.397^{* *}$ & 1 & $0.327^{* *}$ & $0.249 * *$ & $0.183^{* *}$ & $0.145^{* *}$ & -0.052 & $0.221^{* *}$ & -0.027 & $0.240 *$ & $0.175^{*}$ & $0.382^{* *}$ \\
\hline AK & $0.393 *$ & $0.359 * *$ & $0.327 * *$ & 1 & $0.251^{* *}$ & 0.031 & $0.386 * *$ & $0.519 * *$ & $-0.263 * *$ & $-0.100 * *$ & 0.090 & 0.085 & 0.115 \\
\hline $\mathrm{ACu}$ & $0.402 * *$ & $0.571 * *$ & $0.249 * *$ & $0.251 * *$ & 1 & $0.794 * *$ & $0.491 * *$ & $0.488 * *$ & $0.474 * *$ & $-0.159 * *$ & $0.091 *$ & $0.098 * *$ & $0.244 *$ \\
\hline $\mathrm{AFe}$ & $0.338 * *$ & $0.691 * *$ & $0.183^{* *}$ & 0.031 & $0.794 * *$ & 1 & $0.358 * *$ & $0.232 * *$ & $0.703^{* *}$ & $-0.195^{* *}$ & $0.172^{* *}$ & $0.188^{* *}$ & $0.218 * *$ \\
\hline AZn & $0.277^{* *}$ & $0.107^{* *}$ & $0.145^{* *}$ & $0.386^{* *}$ & $0.491^{* *}$ & $0.358 * *$ & 1 & $0.428 * *$ & 0.065 & $-0.247 * *$ & $0.192 *$ & 0.046 & 0.067 \\
\hline $\mathrm{AB}$ & $0.117^{* *}$ & -0.002 & -0.052 & $0.519 * *$ & $0.488^{* *}$ & $0.232 * *$ & $0.428^{* *}$ & 1 & $-0.180 * *$ & $-0.098 * *$ & 0.055 & 0.060 & 0.055 \\
\hline AMn & $0.421 * *$ & $0.811^{* *}$ & $0.221 * *$ & $-0.263 * *$ & $0.474 * *$ & $0.703^{* *}$ & 0.065 & $-0.180 * *$ & 1 & $-0.098 * *$ & $0.198 * *$ & $0.108 * *$ & $0.204 * *$ \\
\hline T-salt & $-0.282 * *$ & $-0.107 * *$ & -0.027 & $-0.100 * *$ & $-0.159 * *$ & $-0.195 * *$ & $-0.247 * *$ & $-0.098 * *$ & $-0.098 * *$ & 1 & $-0.211^{* *}$ & $-0.089 *$ & $-0.401 * *$ \\
\hline NDVI & $0.318 * *$ & $0.284 * *$ & $0.240 *$ & 0.090 & 0.191* & $0.172 * *$ & 0.192* & 0.055 & $0.198 * *$ & $-0.211^{* *}$ & 1 & $0.955^{* *}$ & $0.987 * *$ \\
\hline RVI & $0.300 * *$ & $0.245^{* *}$ & $0.175^{*}$ & 0.085 & $0.098 * *$ & $0.188^{* *}$ & 0.046 & 0.060 & $0.108^{* *}$ & $-0.089 *$ & $0.955^{* *}$ & 1 & $0.946 * *$ \\
\hline Yield & $0.540^{* *}$ & $0.441^{* *}$ & $0.382 * *$ & 0.115 & $0.244 *$ & $0.218^{* *}$ & 0.067 & 0.055 & $0.204 * *$ & $-0.401 * *$ & $0.987 * *$ & $0.946^{* *}$ & 1 \\
\hline
\end{tabular}

Note: Indicates correlation is significant at $5 \%$ probability level; $* *$ indicates correlation is extremely significant at $\quad \mathbf{1 \%} \quad$ probability level

From table 3 we can know: (1)It shows a positive correlation between vegetation indexes and all correlation coefficient are higher. (2) The dependency between remote sensing estimate yield data and soil nutrients data is very well, apart from rapidly available $\mathrm{K}$, available $\mathrm{Zn}$, available $\mathrm{B}$, mostly show significant positive correlation, total salt show a negative correlation with yield, indicates that total salt is main limiting factor which limits crop output. The correlation between remote sensing estimate output data and remote sensing vegetation indexes are all show significant positive correlation, it can preferably illustrate the situation of crop growing.In accordance with related analysis, the paper select remote sensing vegetation index data(NDVI, RVI) which have better correlation with crop output regards them as evaluation criteria so that making a partition of management zone.

\subsection{Management zone partition}


Adopt the method of fuzzy-c mean value clustering to make a analysis for remote sensing data, and select the maximum iteration times is 300 , and convergence domain value is 0.001 , fuzzy weighted index number $\varphi$ was set up by 1.2-2.0, selected fuzzy category number is 2-10 for making fuzzy clustering, finally cluster three sub-zones can be got, management map figure as following figure 1.

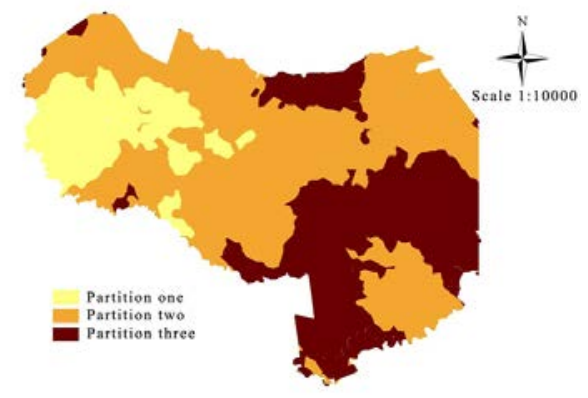

Fig. 1. Management map based on the cluster analysis

\subsection{Management zone evaluation}

Scientific and reliable farmland management zone not only guarantee variation is smaller in the same management zone, but also make the difference in different management zone is significant [9]. Make conventional statistics for remote sensing data, meanwhile, use the method of shortest significant ranges and test for significance on each zone, so the results as follow table 4:

Table 4. Soil and remote sensing data partition attribute statistics and LSD test

\begin{tabular}{cccccc}
\hline & $\begin{array}{c}\text { Sampling point } \\
\text { number }\end{array}$ & Mean value & NDVI & Rariable coefficient(\%) & Mean value \\
Zone1 & 219 & $0.62 \mathrm{aA}$ & $27.31 \%$ & $4.34 \mathrm{bB}$ & $28.07 \%$ \\
Zone 2 & 287 & $0.29 \mathrm{bB}$ & $9.62 \%$ & $1.75 \mathrm{cC}$ & $18.01 \%$ \\
Zone 3 & 223 & $0.63 \mathrm{aA}$ & $10.77 \%$ & $4.60 \mathrm{aA}$ & $20.66 \%$ \\
\hline \multicolumn{2}{l}{ Note: Letters after the means indicate significant difference at 5\%, and 1\% level, respectively }
\end{tabular}

From table 4 we can know: LSD test result indicates that RVI value in three zones partition 1,2,3 all reach to highly significant difference $(P<0.01)$. For NDVI value, the difference in partition 1 and 3 fail to reach significant level $(P>0.05)$, but both reach to highly significant difference with partition 3 .

Table 5. Zoning statistics for soil properties and LSD test

\begin{tabular}{cccccc}
\hline & Sampling point & \multicolumn{2}{c}{ NDVI } & \multicolumn{2}{c}{ RVI } \\
number & Mean value & variable coefficient(\%) & Mean value & variable coefficient(\%) \\
Zone 1 & 251 & $0.5149 \mathrm{abAB}$ & $34.77 \%$ & $3.6599 \mathrm{bB}$ & $37.58 \%$ \\
Zone 2 & 266 & $0.5457 \mathrm{aA}$ & $30.21 \%$ & $3.8825 \mathrm{aA}$ & $36.20 \%$ \\
Zone 3 & 212 & $0.4778 \mathrm{bB}$ & $35.71 \%$ & $3.3936 \mathrm{cC}$ & $39.03 \%$ \\
\hline
\end{tabular}

Note: Letters after the means indicate significant difference at $5 \%$, and $1 \%$ level, respectively

From table 5 we can know that LSD test result show that for RVI value, all values reach to highly significantly difference $(\mathrm{P}<0.01)$.on partition $1,2,3$ three partitions, for NDVI value, the difference between partition 2 and three reach to highly significantly level $(P<0.01)$, however, it fail to reach highly significantly difference between partition 1 and both partition 2 and $3(P>0.05)$.

Table 6. Based on NDVI management partition attribute statistics and LSD test

\begin{tabular}{cccccc}
\hline & $\begin{array}{c}\text { Sampling point } \\
\text { number }\end{array}$ & Mean value & variable coefficient(\%) & Mean value & Variable coefficient (\%) \\
Zone 1 & 189 & $0.2312 \mathrm{cC}$ & $34.38 \%$ & $1.6343 \mathrm{cC}$ & $22.69 \%$ \\
Zone 2 & 329 & $0.5723 \mathrm{bB}$ & $11.18 \%$ & $3.7701 \mathrm{bB}$ & $17.80 \%$ \\
\hline
\end{tabular}




\begin{abstract}
Zone 3
211

$0.6836 \mathrm{aA}$

$3.26 \%$

$5.3276 \mathrm{aA}$

$8.81 \%$

Note: Letters after the means indicate significant difference at $5 \%$, and $1 \%$ level, respectively

From table 6 we can know that take remote sensing data as data sources for dividing management zone, the mean value and nutrients content is the lowest in partition 3 after divided zone is this region , the soil fertility in partition 2 is between partition 1 and partition 3. LSD test result show that for NDVI、RVI value, all values reach to highly significantly difference $(\mathrm{P}<0.01)$ on partition $1,2,3$ three partitions.
\end{abstract}

\title{
3.5 Management zone precision check
}

Volume of production variation is concentrated expression for soil nutrient, crop condition and various factors and its interaction. Therefore, cotton actual output data single factor interpolation in test site was collected in 2011 from the agricultural production management decision section in study area so that obtain spatial variation for management zone, in order to convenient for analyzing, divide three partitions and they are high ( $\left.>6000 \mathrm{~kg} / \mathrm{hm}^{2}\right)$, middle $\left(5250-6000 \mathrm{~kg} / \mathrm{hm}^{2}\right.$ ), low ( $<5250 \mathrm{~kg} / \mathrm{hm}^{2}$ ), and the partition map as following figure 2 .

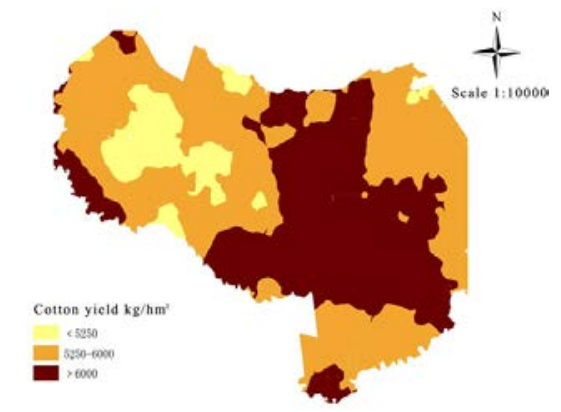

Fig. 2. Precise management zones map Based on the yield

\subsection{Regarding this as basis and check rationality and precision of management divided by those different data sources}

Due to GIS has powerful function with operate raster data, including: Classified method, through classify for pixel value, display special raster data, and this type of special classification can be used to continuous phenomenon( such as suitability), then divide range to several categories and specify color for each category. Hence, separately take soil nutrients, soil combine with remote sensing data, remote sensing vegetation NDVI, cotton actual output as data sources, we can get management partition vector diagram, then import into ArcGIS 9.3, then turn vector data into raster data, and raster set is $100 \mathrm{~m} * 100 \mathrm{~m}$, Rows: 126 , Columns: 165 , total raster number is $126 * 165=20790$. Use Classified shader and classify raster data, but raster image shall keep correspondence with vector management zone map, and then use Reclassified function to implement new value for raster data under the Spatial analysis mode, if classify three categories, each category default value is 1,2,3. Finally, different data sources management zone grey scale image will be got (as following figure 3), right key can open its property table and statistics each category (i.e. raster number in each partition) raster number covered, then statistics result show as following table 7. From figure 2 we can find out obtained management raster grey image from different data sources (figure 3-A) is comply with obtained management zone grey image (figure 3-B) from actual output classification, only from image we can't find out which is more advantage. Therefore, make raster calculate and statistics (as following table7) for test its precision based on actual production each region raster numbers.

Table 7. Management partition grid number statistics of different data source partition 


\begin{tabular}{ccccc}
\hline Data source & Zone1 & Gone2 & Zone3 & Total \\
NDVI & 4975 & 6352 & 9463 & 20790 \\
$\begin{array}{c}\text { Actual out- } \\
\text { put }\end{array}$ & 3789 & 11451 & 5550 & 20790 \\
\hline
\end{tabular}

Table 8. Results of grid computing statistical

\begin{tabular}{ccccccc}
\hline Data & \multicolumn{7}{c}{ the grid number of conformity with actual yield } & \multirow{2}{*}{ Grid number } & conformity \\
source & Zone1 & Zone2 & Zone3 & Total & & \\
NDVI & 3789 & 6352 & 5550 & 15691 & 20790 & $75.47 \%$ \\
\hline
\end{tabular}
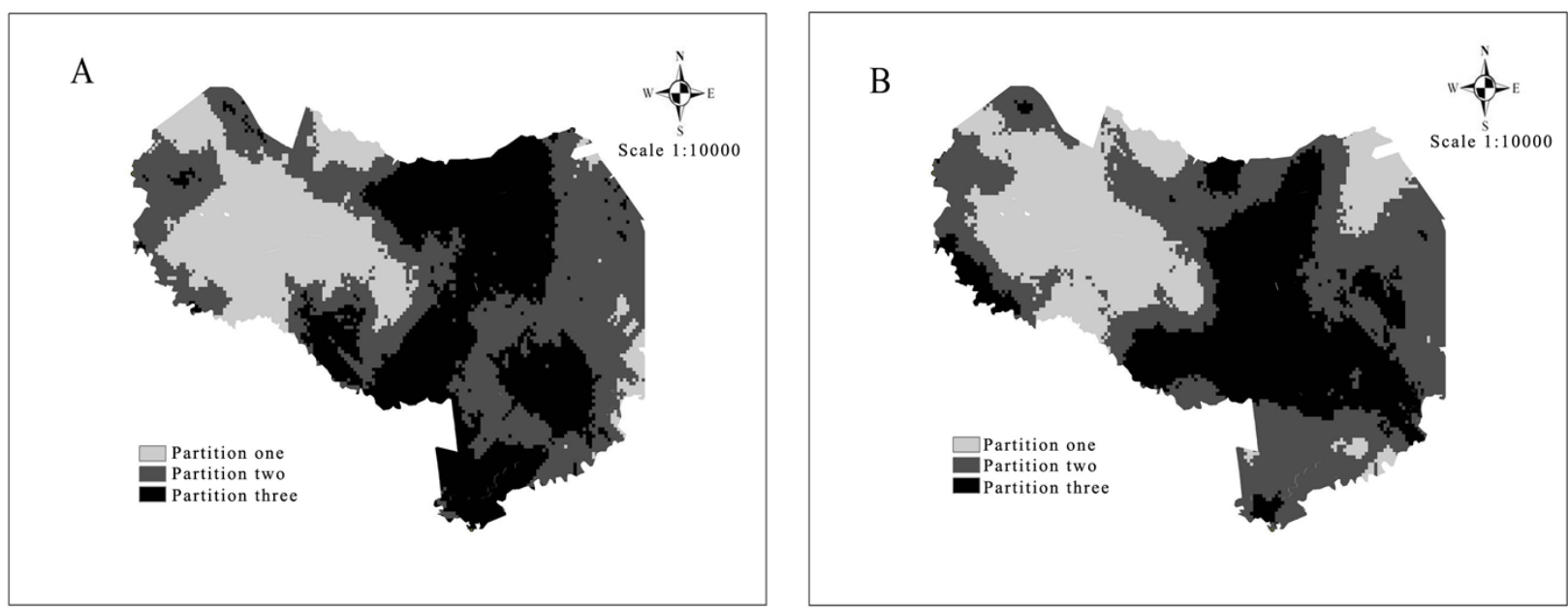

Fig. 3. Management raster image based on different data source Note: A- NDVI data ,B-actual yield as data sources

From table 8 we can see that the conformity reaches to $75.47 \%$ which through remote data NDVI as data for dividing management. Indicate that the result of management zone which was divided by soil data combine with remote sensing for precision management zone is more reasonable and more high-precision than only take soil nutrients as data for dividing management, and which can better explain distribution of soil fertility.

\section{Conclusion}

Respectively take remote sensing data as data resources and use FCM for making precise management zone, then the study zone was divided to 3 precision nutrient management zones and the partition overlap is small and the subordinate relationship is obvious. In order to guarantee reasonable of management zone, so make statistics and analysis to nutrient mean value in each management partition and use LSD method for making significance testing. Generally, after divided management zone, nutrient content index of variable coefficient in each partition have decreased on varying degree, which spatial distribution towards the same direction extend, and difference between different management partitions is obvious, spatial difference of nutrient contents in same partition is smaller. We shall adopt the same fertilizing amount in same management partition when we use management zone for fertilize, but we shall implement differentiation variable rate fertilization management in different partitions.

Regarding the management zone obtained data sources from actual output as basis, make quantization statistic analysis for management zone precision which obtained from different data sources. Result indicate that the conformity reaches to $75.47 \%$ which through remote data NDVI as data for dividing management. The result is similar with obtained result from Sun X Y, Huang, 
$\mathrm{Y}$ etc institute. Consequently, it have higher reliability for making precise management zone, which take remote sensing vegetation index as data sources, to large farmland under the mode of oasis farming.

\section{CONFLICT OF INTEREST}

The author confirms that this article content has no conflict of interest.

Acknowledgements. This work was financially supported by project of National High-tech R\&D Program of China (863 Program)-2012AA101902.

\section{References}

1. Koch B., Khosla R., Frasier W.M.et al:Economic feasibility of variable-rate nitrogen application utilizing site-specific management zones. Agronomy Journal. 96: 1572-1580 (2004)

2. Doerge T.A.: Defining management zones for precision agriculture.Crop Insights. 8(21):1-5(1998)

3. Lai Xianqi: Oasis agriculture of china. In: Bei-jing:China Agricultural Press (2005)

4. Wang Hailjiang, Cui Jing, Chen Yan, Lv Xin. Classification of Management Zones for Soil Nutrients in Cotton Land Based on Fuzzy Clustering Analysis[J]. Cotton Science. 22(4):339-346 (2010)

5. Tan Manzhi, Chen Jie, Xu Fangming,et al.:Spatial prediction of soil heavy metal pollution based on fuzzy set theory. ActaPedologica Sinica. 43(3):389-396 (2006)

6. Mcbratney A.B., Moore A.W.: Application of fuzzy sets to climatic classification. Agricultural \& Forest Meteorology, 35(1-4):165-185 (1985)

7. Bragato G.:Fuzzy continuous classification and spatial interpolation in conventional soil survey for soil mapping of the lower Pi-ave plain. Geoderma. 118:1-16 (2004)

8. Song Xiaoyu, Wang Jihua, Liu Liangyun, et al.:Research of Management Zones Generating Based on Quickbird Imagery. Scientia Agricultura Sinica. 40(9):1996-2006 (2007)

9. Qiu Weiwen :Spatial variability of soil nutrients in farmland feature and partition management research. Liaoning: Shenyang Agricultural Uinversity (2003) 